\title{
USING BREATHING AND MEDITATIVE TECHNIQUES TO DEAL WITH UNCERTAINTY AND ANXIETY: A PERSONAL EXPERIENCE
}

\author{
GEETA SHYAM ${ }^{1}$ \\ ${ }^{1}$ Monash University, Faculty of Law, Wellington Road, Clayton VIC 3800, Australia. ORCID: 0000-0002- \\ 4797-9573, Email: geetashree.shyam@monash.edu
}

\begin{abstract}
The scale of disruption caused by the COVID-19 pandemic is expected to adversely affect the mental health of a large number of people. In this Note, the author shares her strategies for dealing with uncertainty and anxiety. Recounting her personal experiences, she reveals how simple breathing exercises and meditation practices helped her accept and respond to a traumatic experience as well as an unexpected illness. A number of studies appear to support the view that breathing exercises and meditation can help people manage anxiety. It is suggested that these studies highlight the relevance and value of these practices in the current distressing conditions. KEYWORDS: anxiety, COVID-19, meditation, breathing, mindfulness
\end{abstract}


The coronavirus (COVID-19) pandemic is having a profound impact on our social, economic and political lives. It has disrupted our normal ways of living, restricting freedoms and social interactions that we had taken for granted. Many are losing financial security, and many are being challenged with new working conditions and arrangements. Businesses are shutting their doors for an unknown period of time, and employers are making heartbreaking decisions to lay off their workers in the midst of a crisis. Hundreds of thousands of people are being treated for COVID-19, while others are traumatised by the possibility of becoming infected. Many have lost family members and friends to the mysterious new illness, while countless others have been separated from their loved ones, potentially for months. All the while, news of the misery unfolding throughout the globe is available at our fingertips. Amidst these testing times, stress and anxiety are common experiences of people across the world.

As the COVID-19 pandemic forces us to accept our unexpected losses and adapt to an unfamiliar and potentially lonely lifestyle within a very short period of time, we have to be wary of the toll these unplanned transitions might take on our mental health. Indeed, the Australian Government recognised the threat that COVID-19 poses to the mental health and wellbeing of people when it announced a $\$ 74$ million package to boost mental health services during the crisis (Australian Department of Health 2020).

The uptake of these professional mental health services by those struggling with stress, anxiety, trauma and other mental health illnesses should be encouraged. However, as the availability and accessibility of such services will vary from place to place (and country to country), not everyone will be able to take advantage of these crucial resources. Many may not be aware of the help that is available, and many will not access the services until things start to get out of hand. Cultural and social stigma may also deter people from seeking timely help.

During these turbulent times, it helps to develop some resilience and coping strategies for the present-day adversities. Doing so on an individual basis can foster a more adaptable and healthier society, thus reducing the burden on our health and welfare systems.

I personally have found breathing exercises and meditation practices to be helpful in dealing with anxiety and trauma. I first learnt basic breathing and meditation techniques from a relative in 2016. He taught my husband and I some simple breathing exercises and generously offered to guide our meditation on a few occasions. The relative pointed out our tendency to develop shallow breathing as we grow out of our infancy, and explained the benefits of slowing and deepening our breaths. My husband tested the theory using his smart watch - his heart rate reduced after a minute of deep breathing. He later used a blood pressure machine to test the impact of deep breathing, and again found a positive result. We were convinced by the immediate benefits we were seeing and feeling.

I started practicing these techniques three to four times a week. I started slowly - I spent 10 minutes doing breathing exercises and 10 minutes on meditation. I immedi- 
ately started to feel more relaxed and lighter. The practices enhanced my mental clarity, helping me resolve mental blocks while I was undertaking my doctoral research. My sinuses and asthma also improved. The benefits I was experiencing motivated me to continue the practices on a more regular basis, and to expand the amount of time I dedicated to these exercises.

The most powerful benefits were felt during times of my own crisis. About three months after I had been introduced to breathing exercises and meditation, I witnessed a horrific incident. While having lunch with a colleague on a beautiful Melbourne summer day in 2017, we watched in horror as a car mowed down people on a footpath on the opposite side of the road. Loud thumping noises, people flying in the air. Within seconds, the car had disappeared. My colleague and I crossed the road to offer assistance to the injured, but it was a lot to take in when we got there. A person was already deceased, while others were lying on the ground in shock and pain. At that point we did not know if this was a terrorist attack, a drink and driving case or an innocent accident. Because we were only at the tail end of the homicidal driver's carnage, it took a while for emergency services to arrive. People around me were distraught, including my colleague who desperately ran from one injured person to another to offer help. Crowds were building. Some were frantically trying to call the ambulance, while others were trying to contact their family and friends. For a long time, we remained on alert because we did not know if someone would return with knives and guns. At this point, I remember shifting my focus to my breath.

I slowed my breathing, which helped me calm my mind. I remember telling myself to accept what had just happened, even if it was really unpleasant and made no sense to me. Once I was able to accept that this awful incident had occurred, I was able to move to a responsive (rather than reactive) state of mind. The pause also allowed me to distinguish between things that were in my control and things that were not in my control. In that chaotic setting, I then started making calculated decisions about my own welfare, how to support my colleague who was clearly very distressed, when and how to communicate with my family and alleviate their panic, and who I would reach out to for my own support.

The days that followed were challenging. Flashbacks kept me awake at night. They subsided within weeks, but my fear and discomfort in public places lingered for a while. Even in places that cars could not access, I would constantly keep an eye out for escape routes. Again, in such situations, I kept shifting my focus to my breath. I kept introspecting and found that watching my thoughts and emotions in these moments stopped them from running wild. I kept reminding myself that I did not need to be defined by this experience alone. I motivated myself to remain upbeat and joyful, because I knew my family would suffer if I did not get through this. I consciously chose not to watch or read the news for some time, as the incident kept being replayed for a number of days. Gradually, the impact of the incident on me started to diminish. I had promised myself that I would seek professional counselling if I was not coping, but fortunately, I did not end up needing that level of help.

More recently, I was again reminded of the benefits of meditation and breathing exercises during times of uncertainty and pain. After several invasive but unhelpful 
scans, I was diagnosed with severe endometriosis in 2019. By then, my menstrual pain had reached the point where it prevented me from walking even a few meters with a straight back. While I knew there was a good explanation for it, I was not expecting such a dramatic diagnosis. A scan at a specialised clinic was able to tell me very quickly that my endometriosis had spread to my bowel. What made things more difficult is that I was left in a position of uncertainty. My surgery was a good few months away, and my gyneocologist and colorectal surgeon were not able to tell me what my treatment and prognosis would be until they actually carried out the operation. I was told that depending on what they would find during the surgery, recovery would take either a week or two months. The latter outcome had obvious implications for my employment and quality of life.

I had to prepare for the worst while hoping for the best. Again, meditation and breathing exercises helped me accept the uncertainties and inconveniences that came with my diagnosis. The exercises calmed my mind whenever I found myself worrying about all the different possibilities that may or may not eventuate. It also helped put things into perspective. My husband and I made a conscious decision to have open conversations with our family and friends about my diagnosis to help break the taboo about women's health issues. We were humbled by how our family and friends, including the males, responded and rallied around us for support. Life did not stop, and ironically, some of my best memories were formed in that period of uncertainty. When I wasn't in pain, I made sure I was making the most of my mobility by indulging in my hobbies and spending as much time as possible with loved ones. I realised the impact that a smile on my face had on my loved ones. Even as I was being taken into the surgical theatre, I made sure I turned around and gave a cheeky smile and wave to my husband, leaving him with no choice but to smile back.

Luckily, despite being in surgery for four and a half hours, I did not end up requiring any severe surgical procedures. The first thing I remember doing when I gained sufficient consciousness was to focus on my breathing. Throughout the day, I kept checking my breathing and practicing deep breathing. Nurses were impressed with my blood pressure for the duration of my stay in hospital. They helped me stand on my feet within hours of the surgery, even if it was just for a few minutes. The nurses were also really happy with my pain management. They were comfortable sending me home the next day without prescribing any painkillers; over the counter pain medication was sufficient for my pain. Maybe my condition had not been that bad after all. In my follow-up appointment a week later though, my gynaecologist explained the scoring system they use to categorise the severity of endometriosis. Anything over 40 is considered Stage Four, the most severe. The score he gave me was 114 .

I am not suggesting that deep breathing and meditation alone helped manage my anxieties and pain during the entire process. There were other lifestyle factors that probably played an important role. I exercised regularly in the months leading up to my surgery. Diet is likely to have played a role as well. However, it is hard for me to deny the impact of my breathing and meditation exercises.

Of course, the conclusions I have drawn from my own experiences have not been scientifically validated. Nevertheless, a number of studies do support these ideas. Some 
studies have found a reciprocal relationship between breathing and anxiety disorders (Paulus 2013). There is evidence suggesting that breathing therapy and retraining reduce breathing frequency (Han et al 1996) and improve breathing patterns (Tweedale, Rowbottom and McHardy 1994). Deep breathing or relaxation breathing exercises have been shown to reduce anxiety levels in range of different contexts, including hospitalised older adults (Neeru et al 2015), asthmatic children (Ching et al 2009), burn patients (Park, Oh and Kim 2013), adolescents (Joshi 2014), cancer patients undergoing chemotherapy (Hayama and Inoue 2012), children sitting for tests (Khng 2017) and musicians delivering stressful performances (Wells et al 2012). Controlled breathing exercises have been found to reduce anxiety and depression in chronic obstructive pulmonary disease (COPD) patients (Valenza et al 2014). When combined with meditation, breathing exercises have been found to have reduced the anxiety of social work interns (Decker et al 2019). Breathing exercises, combined with walking, has also reduced anxiety in COPD patients (Lin et al 2018) and heart failure patients (Teng, Yeh and Weng 2018). There is still a lot that needs to be scientifically understood in terms of the relationship between breathing and anxiety symptoms (Tiwari and Baldwin 2012; Paulus 2013), and the role that other factors, such as personal expectations, play in determining the outcome of undertaking breathing exercises (Kim, Roth and Wollburg 2015). However, the data that is currently available does provide some validity to the experiences of people like me who feel they have benefited from breathing exercises.

Similarly, encouraging results have been produced in studies examining the effects of meditation. Regular practice of meditation has been associated with reduced levels of anxiety (Delmonte 1985; Carpena, Tavares and Menezes 2019). Different types of meditation have been shown to reduce anxiety in a variety of contexts, such as in full time workers (Manocha et al 2011), drivers (Mitrofan 2014), nursing students (Chen et al 2013; Stinson et al 2020), adolescent psychiatric patients (Blum et al 2019), heart disease patients (Taco'n et al 2002), cancer patients undergoing radiation therapy (Kim et al 2013) and musicians (Lin et al 2008). Meditation has been found to reduce depression and improve concentration (Leite et al 2010; Menezes and Bizarro 2015). Meditation combined with an exercising regime has also been found to lessen anxiety symptoms (Edwards, Rosenbaum and Loprinzi 2018). Further, meditation has been associated with improved occupational functioning and decreased absenteeism (Hoge et al 2017). As with scientific literature on breathing exercises, there are still gaps in existing research that warrant further investigation (Toneatto and Nguyen 2007; Hussain and Bhushan 2010). Fortunately, meditation is increasingly becoming the subject of scientific and medical inquiries (Hussain and Bhushan 2010).

It is perhaps in light of these studies that reputable organisations such as Headspace (2020), Havard Medical School (2020) and the United Nations (2020) are suggesting meditation and controlled breathing as strategies for coping with COVID-19 related anxiety. These strategies will not replace the professional mental health services. Rather, they can play a supplementary role and hopefully reduce our reliance on services that are subject to finite government funding. 
Where does one get started, particularly at a time when sitting in a classroom has become extremely difficult, if not impossible? Thanks to the digital age, there are a range of resources that are easily accessible. Experts and various groups, inspired by both spiritual and secular practices, provide a wealth of information as well as guided meditations through various online platforms, such as websites, ebooks and YouTube videos. Guided meditations can additionally be accessed through numerous mobile phone apps. Some meditation teachers have also started online classes in response to the COVID-19 lockdowns. Or, like myself, some people may benefit from speaking to a relative or friend who may be able to provide an introduction to simple breathing and meditation techniques.

While the term meditation might imply a single methodology, there are several different types and goals of meditation (Delmonte 1985; La Torre 2001). Some people close their eyes to meditate, while others use visual tools. Some focus on a particular point in their body, while others focus on the more subtle breath. Some incorporate sounds into their practice, while others aspire for silence. Some run their fingers through rosary beads, while others strive for stillness. Some meditate to empty their minds, while others meditate to concentrate their minds on something. Some use meditation to become more aware of their thoughts and emotions, while others meditate for a higher spiritual purpose. Some meditate on the notion of "zero", while others meditate on the idea of infinity. Some prefer to meditate in groups, while others embrace solitude.

The vast range of approaches and schools can be intimidating. Many people prefer to strictly follow a specific technique, enabling them to progress with their practices in a steady and disciplined manner. I, on the other hand, keep myself open to new approaches, as I tend to struggle when I box myself into a particular category. By taking a flexible approach, I find something new to learn and adopt from every technique. Others may benefit from experimenting as well, at least until they can find a method that works well for them. The important part is to set aside some time to make a start.

Whichever means and methods one selects, I hope it enables greater acceptance, adaptability and resilience in this new world we are suddenly finding ourselves in.

FUNDING: This research received no external funding.

CONFLICT OF INTEREST: The author declares no conflict of interest.

\section{REFERENCES}

"Fact Sheet: Coronavirus (COVID-19) National Health Plan." Australian Department of Health. Retrieved March 30, 2020 (https://www.health.gov.au/sites/default/ files/documents/2020/03/covid-19-national-health-plan-supporting-the-mental-health-of-australians-through-the-coronavirus-pandemic.pdf). 
Blum, Harrison, Christopher Rutt, Carol Nash, Victoria Joyce and Ralph Buonopane. 2019. "Mindfulness Meditation and Anxiety in Adolescents on an Inpatient Psychiatric Unit.” Journal of Health Care Chaplaincy 1-19.

Carpena, Marina Xavier, Patrice de Souza Tavares and Carolina Baptista Menezes. 2019. “The Effect of a Six-Week Focused Meditation Training on Depression and Anxiety Symptoms in Brazilian University Students with 6 and 12 Months of Follow-up." Journal of Affective Disorders 246:401-407.

Chen, Yu, Xueling Yang, Liyuan Wang and Xiaoyuan Zhang. 2013. “A Randomized Controlled Trial of the Effects of Brief Mindfulness Meditation on Anxiety Symptoms and Systolic Blood Pressure in Chinese Nursing Students.” Nurse Education Today 33:1166-1172.

Chiang, Li-Chi, Wei-Fen Ma, Jing-Long Huang, Li-Feng Tseng and Kai-Chung Hsueh. 2009. "Effect of Relaxation-Breathing Training on Anxiety and Asthma Signs/ Symptoms of Children with Moderate-to-Severe Asthma: A Randomized Controlled Trial.” International Journal of Nursing Studies 46:1061-1070.

Decker, James T, Jodi L Constantine Brown, Wendy Ashley and Allen E Lipscomb. 2019. "Mindfulness, Meditation, and Breathing Exercises: Reduced Anxiety for Clients and Self-Care for Social Work Interns.” Social Work with Groups 42(4): 308-322.

Delmonte, M M. 1985. “Meditation and Anxiety Reduction: A Literature Review”. Clinical Psychology Review 5:91-102.

Edwards, Meghan K, Simon Rosenbaum and Paul D. Loprinzi. 2018. "Differential Experimental Effects of a Short Bout of Walking, Meditation, or Combination of Walking and Meditation on State Anxiety Among Young Adults.” American Journal of Health Promotion 32(4):949-958.

Han, J N, K Stegen, C De Valck, J Clement and K P Van de Woestijne. 1996. “Influence of Breathing Therapy on Complaints, Anxiety and Breathing Pattern in Patients with Hyperventilation Syndrome and Anxiety Disorders." Journal of Psychosomatic Research 41(5):481-493.

“Coping with Coronavirus Anxiety.” 2020. Harvard Medical School. Retrieved on March 30, 2020 (https://www.health.harvard.edu/blog/coping-with-coronavirus-anxiety-2020031219183).

Hayama, Yuka and Tomoko Inoue. 2012. “The Effects of Deep Breathing on 'Tension-Anxiety' and Fatigue in Cancer Patients Undergoing Adjuvant Chemotherapy." Complementary Therapies in Clinical Practice 18:94-98.

“We're Here for You.” 2020. Headspace. Retrieved March 30, 2020 (https://www.headspace.com/covid-19).

Hoge, Elizabeth A, Brittany M. Guidos, Mihriye Mete, Eric Bui, Mark H. Pollack, Naomi M Simon and Mary Ann Dutton. 2017. Journal of Psychosomatic Research 95:7-11. Hussain, Dilwar and Braj Bhushan. 2010. "Psychology of Meditation and Health: Present Status and Future Directions.” International Journal of Psychology and Psychological Therapy 10(3):439-451.

Joshi, Rupali. 2014. "Stress, Depression and Anxiety and Breathing Exercise Among College Going Late Adolescents.” International Journal of Education \& Management Studies 4(1):01-11. 
Khng, Kiat Hui. 2017. “A Better State-of-Mind: Deep Breathing Reduces State Anxiety and Enhances Test Performance through Regulating Test Cognitions in Children, Cognition and Emotion." Cognition and Emotion 31(7):1502-1510.

Kim, Sunyoung, Walton T Roth and Eileen Wollburg. 2015. "Effects of Therapeutic Relationship, Expectancy, and Credibility in Breathing Therapies for Anxiety.” Bulletin of the Menninger Clinic 79(2):116-130.

Kim, Yeon Hee, Hwa Jung Kim, Seung Do Ahn, Yun Jeong Seo and So Hee Kim. 2013. "Effects of Meditation on Anxiety, Depression, Fatigue, and Quality of Life of Women Undergoing Radiation Therapy for Breast Cancer.” Complementary Therapies in Medicine 21:379-387.

La Torre, Mary Anne. 2001. "Meditation and Psychotherapy: An Effective Combination.” Perspectives in Psychiatric Care 37(3):103-106.

Leite, José Roberto, Felipe Leite de Moraes Ornellas, Tascila Mary Amemiya, Anna Alice Figueirêdo de Almeida, Arnaldo Aparecido Dias, Rui Afonso, Stephen Little and Elisa Kozasa. 2010. "Effect of Progressive Self-Focus Meditation on Attention, Anxiety, and Depression Scores.” Perceptual and Motor Skills 110(3):840848.

Lin, Feng-Lien, Mei-Ling Yeh, Yeur-Hur Lai, Kuan-Chia Lin, Chong-Jen Yu and Jung-San Chang. 2019. “Two-month Breathing-Based Walking Improves Anxiety, Depression, Dyspnoea and Quality of Life in Chronic Obstructive Pulmonary Disease: A Randomised Controlled Study.” Journal of Clinical Nursing 28: 3632-3640.

Lin, Peter, Joanne Chang, Vance Zemon and Elizabeth Midlarsky. 2008. "Silent Illumination: A Study on Chan (Zen) Meditation, Anxiety, and Musical Performance Quality.” Psychology of Music 36(2):139-155.

Manocha, R, D Black, J Sarris and C Stough. 2011. "A Randomized, Controlled Trial of Meditation for Work Stress, Anxiety and Depressed Mood in Full-Time Workers." Evidence-Based Complementary and Alternative Medicine 3:1-8.

Menezes, Carolina Baptista and Lisiane Bizarro. 2015. "Effects of a Brief Meditation Training on Negative Affect, Trait Anxiety and Concentrated Attention.” Paidéia 25(62): 393-401.

Mitrofan, Laurentiu, Mihaela Chraif, Florinda Golu and Emil-Razvan Gatej. 2014. “The Unifying Creative-Meditation Technique and Physiological Measurement of Anxiety in Romanian Amateur Drivers.” Procedia - Social and Behavioral Sciences 127: $823-827$.

Neeru, D C Khakha, S Satapathy and A B Dey. 2015. “Impact of Jacobson Progressive Muscle Relaxation (JPMR) and Deep Breathing Exercises on Anxiety, Psychological Distress and Quality of Sleep of Hospitalised Adults." Journal of Psychosomatic Research 10(2):211-223.

Park, Eunok, Hyunjin Oh and Taeim Kim. 2013. “The Effects of Relaxation Breathing on Procedural Pain and Anxiety During Burn Care.” Burns 39:1101-1106.

Paulus, Martin P. 2013. "The Breathing Conundrum - Interoceptive Sensitivity and Anxiety.” Depression and Anxiety 30:315-320.

Stinson, Cynthia, Eileen Deges Curl, Gina Hale, Stacey Knight, Cynthia Pipkins, Iva Hall, Kelli White, Nancy Thompson and Christy Wright. 2020. Nursing Education 
Perspectives (forthcoming).

Tacón, Anna M, Jacalyn McComb, Yvonne Caldera and Patrick Randolph. 2003. "Mindfulness Meditation, Anxiety Reduction, and Heart Disease: A Pilot Study." Family \& Community Health 26(1):25-33.

Teng, Hsiu-Chin, Mei-Ling Yeh and Mei-Hua Wang. 2018. "Walking with Controlled Breathing Improves Exercise Tolerance, Anxiety, and Quality of Life in Heart Failure Patients: A Randomized Controlled Trial.” European Journal of Cardiovascular Nursing 17(8): 717-727.

Tiwari, Nupur and David S Baldwin. 2012."Yogic Breathing Techniques in the Management of Anxiety and Depression: Systematic Review of Evidence of Efficacy and Presumed Mechanism of Action." Mind \& Brain, the Journal of Psychiatry 3(1):1422.

Toneatto, Tony and Linda Nguyen. 2007. "Does Mindfulness Meditation Improve Anxiety and Mood Symptoms? A Review of the Controlled Research." Canadian Journal of Psychiatry 52(4):260-266.

Tweeddale, P M, I Rowbottom and G J R McHardy. 1993. "Breathing Retraining: Effect on Anxiety and Depression Scores in Behavioural Breathlessness." Journal of Psychosomatic Research 38(1): 11-21.

“Wellbeing tips for UN Personnel.” 2020. United Nations. Retrieved March 30, 2020 (https://www.un.org/en/coronavirus/wellness).

Valenza, Marie Carmen, Geraldine Valenza-Pena, Irene Torres-Sanchez, Emilio Gonzalez-Jimenez, Alicia Conde-Valero and Gerald Valenza-Demet. 2014. "Effectiveness of Controlled Breathing Techniques on Anxiety and Depression in Hospitalized Patients with COPD: A Randomized Clinical Trial.” Respiratory Care 59(2):209-215.

Wells, Ruth, Tim Outhred, James A J Heathers, Daniel S Quintana and Andrew H Kemp. 2012. "Matter Over Mind: A Randomised-Controlled Trial of Single-Session Biofeedback Training on Performance Anxiety and Heart Rate Variability in Musicians.” PLoS One 7(10): Retrieved March 28, 2020 (https://journals.plos.org/ plosone/article?id=10.1371/journal.pone.0046597).

\section{BIOGRAPHICAL NOTE}

Geeta Shyam is a Teaching Associate and Research Assistant at Monash University, Australia.

OPEN ACCESS: This article is distributed under the terms of the Creative Commons Attribution Non-commercial License (CC BY-NC 4.0) which permits any non-commercial use, and reproduction in any medium, provided the original author(s) and source are credited. 
